\title{
Las "Noticias de la península americana de California" de Juan Jacobo Baegert. Influencias y contexto de un documento de uso etnohistórico
}

\author{
Rogelio E. Ruiz Ríos"
}

Fecha de recepción: 15 de agosto de 2017. Fecha de aceptación: 1 de noviembre de 2017

\begin{abstract}
Resumen
El legado testimonial de Juan Jacobo Baegert, misionero jesuita de origen alemán con una larga experiencia en la península de California, ha sido usado en años posteriores como una fuente privilegiada para el conocimiento etnohistórico de los grupos indígenas que habitaban la región durante la etapa de conquista. En vista de los usos etnohistóricos que se le han dado a dicha obra, en este artículo me propongo discutir las influencias y el contexto intelectual, ideológico e histórico que influyeron en las intenciones y elecciones de su autor para escribir y publicar dicha obra. Este es un tema de importancia tanto para la memoria de los actuales habitantes de la península de Baja California como para pensar críticamente los procesos de construcción del conocimiento etnohistórico en general, desde una perspectiva poscolonial.
\end{abstract}

Juan Jacobo Baegert's “Noticias de la península americana de California". Influences and context of a document with ethnohistorical value

\begin{abstract}
In recent years the testimonial legacy of Juan Jacobo Baegert, well-know Jesuit missionary of German origin with a long experience in the California Peninsula, has become a privileged source to the ethno-historical knowledge of the indigenous groups who inhabited the area during the conquest period. Since there are many ethnohistorical studies about it, this paper focuses in the intellectual, ideological and historical contexts that influenced the author while writing, and later published, the above mention written work. At present the subject is relevant because it enhances critical thinking around the construction of memory of the Baja California inhabitants, as well as over the process of construction of ethnohistorical knowledge from a postcolonial point of view.
\end{abstract}

Palabras clave

jesuitas misioneros Baja California indígenas

Key words

Jesuits missionaries Baja California Indigenous 


\section{Introducción}

En 1942 con el título de Noticias de la península americana de California el arqueólogo alemán Paul Kirchhoff publicó, por vez primera, completo en español el libro Nachrichten von der Amerikanischen Halbinsel Californien mit einem zweyfachen Anhand falscher Nachrichten, autoría del jesuita Juan Jacobo Baegert (Johann Jakob Baegert). La traducción al español estuvo a cargo de Pedro R. Hendrichs del original en lengua germana editado en Mannheim en 1771. La obra en cuestión ha sido constituida como una de las fuentes principales para la investigación etnográfica e histórica sobre las sociedades ágrafas que habitaban la península de Baja California al momento del encuentro con los conquistadores europeos.

Esto obedece a que el texto de Baegert es una de las escasas fuentes con valor testimonial y por ello se le ha valorado e interpretado como un documento privilegiado para conocer y comprender a las sociedades indígenas durante el proceso colonizador que dirigieron los jesuitas en Baja California. En vista de la relevancia adquirida por este tipo de fuentes, que hablan de quienes los misioneros jesuitas ayudaron a construir discursivamente como los Otros, es necesario indagar en torno a los autores de esas miradas, quienes elaboraron tales observaciones en un determinado tiempo, espacio y flujo de ideas que fueron soporte de sus obras y enmarcaron sus intenciones y legado. A propósito de su historia de la locura, que definió como una "historia de lo otro", Michel Foucault preguntaba: “¿A partir de qué a priori histórico ha sido posible definir el gran tablero de las identidades claras y distintas que se establece sobre el fondo revuelto, indefinido, sin rostro y como indiferente, de las diferencias?" (Foucault 1998: 9). A lo que respondía que se generaba una distinción entre lo interior y lo externo, que a la vez que se "reducía" la alteridad del Otro se le familiarizaba mediante la reducción a través de categorías y de clasificaciones para destacar su "extrañeza" y hacerla manejable. Las respuestas estaban en el "pensamiento clásico" y en el umbral que lo separó de la Modernidad entre los siglos XVII y XVIII. Ese a priori sustancialista y esencialista labrado desde la Antigua Grecia conduce hasta Aristóteles; en él se basaron a partir de los siglos XII y XIII las articulaciones discursivas que fincaron las identidades en un mar de diferencias hasta las rupturas epistémicas que forjaron el enciclopedismo y la ciencia constitutiva de la noción de lo natural y la naturaleza.

Buena parte de la documentación legada por los misioneros jesuitas acerca de su labor en el Nuevo Mundo describe sus experiencias en zonas abiertas al

1. Por "zonas de contacto" (contact zones en el original) asumo la definición de Mary Louise Pratt para aludir a espacios sociales donde se disparan los encuentros, choques y disputas culturales entre pueblos separados geográfica e históricamente, a menudo vinculados por relaciones de dominación y subordinación bastante asimétricas como el colonialismo, la esclavitud o sus secuelas, tal como se viven hoy día en el planeta. Las autora aclara que emplea el término como sinónimo de "frontera colonial" (colonial frontier), pensada la noción de contacto para dar cuenta de la dimensión interactiva y de improvisación implícita en los encuentros coloniales (Pratt 2003: 4, 6). He revisado varias ediciones de este libro (una en inglés de 2003 y dos español, de 1997 y 2010), y las cito según el caso. contacto, ${ }^{1}$ entre los representantes de la cristiandad y el complejo entramado de agentes sociales sometidos de manera violenta al proceso civilizatorio que desde el siglo XVI expandió el modelo social cristiano, europeo, occidental y capitalista. En las zonas de contacto, como en ninguna otra, las relaciones de traducción cultural se revelaron problemáticas dentro de un orden vertical, inequitativo, excluyente y expoliador. Como se ha señalado con precisión, la traducción debe entenderse como un intento de establecer equivalencias y comprensiones entre sistemas de signos, los signos como procesos y las funciones del signo mediante criterios que trascienden lo lingüístico para dar lugar a procesos de decodificación y recodificación (Bassnett, 2002: 22 y 24).

Los textos de Baegert y de otros misioneros jesuitas centrados en sus experiencias en los confines del Imperio español cumplen la función de artefactos culturales que dan cuenta de las formas, innovaciones e intenciones implícitas y derivadas de las prácticas de traducción cultural llevadas a cabo en las zonas de contacto bajo su supervisión. En el caso de Baegert, sus escritos permiten 
adentrarse en el conocimiento de las relaciones tejidas entre colonizadores y las sociedades ágrafas que habitaban la península bajacaliforniana. Frente a la ausencia de escritos propios producidos por los miembros de esos pueblos originarios durante la etapa de contacto, los testimonios jesuitas son una de las escasas evidencias al respecto. Por tal motivo, la obra de Baegert ha sido concebida historiográfica y etnográficamente como una fuente autorizada al ser una de las pocas ranuras por las que puede asomarse el ojo del investigador en su afán por conocer, comprender e interpretar las formas de organización social y cultural de estos grupos humanos, la mayoría de ellos extintos tras el encuentro con los conquistadores.

Es oportuno tomar en cuenta el hiato cultural existente entre los dos grupos humanos inmersos en procesos culturales -o por decirlo a la manera de Norbert Elias: en "procesos civilizadores" - diferenciados a partir de la posesión y ausencia de un sistema de escritura como el que se presentó durante la conquista de la Baja California -o de "conquista y aculturación" como lo designara un eminente historiador del septentrión novohispano de comprobada aversión por los planteamientos teóricos posestructuralistas. ${ }^{2}$

El experto en neurociencias Merlin Donald ha planteado que la escritura, al igual que otros tipos de dispositivos externos como los instrumentos científicos, han alterado drásticamente los tipos de representaciones que pueden ser reconstruidas y recordadas. En su opinión, esto marcó un gran cambio en la historia de la especie humana que así pudo transitar de la "memoria biológica" a contar con un "almacén simbólico externo". El resultado de esta transformación fue que en el mundo actual contamos con oportunidades para almacenar información con capacidad virtualmente ilimitada, de amplia accesibilidad y durabilidad que nos proporcionan nuevas formas de representación del mundo (Donald, 2004: 380). Además de tener en cuenta esta diferencia significativa respecto a la escritura entre los representantes europeos y los indígenas de la Baja California durante la etapa de contacto, había una marcada distancia en sus respectiva "conciencia del tiempo". Para el caso de los misioneros esta se expresaba en las formas y mecanismos diseñados para medir su "paso", lo que Norbert Elias designara como "regulación social del tiempo" (Elias, 2015: 46-47), mientras que entre los grupos indígenas de la península clasificados en la categoría de "cazadores recolectores" aún falta ahondar en torno a ello. Es importante acentuar las clasificaciones que desde los discursos etnológicos e históricos se le han endilgado a los grupos humanos porque, como señala una estudiosa de los grupos indígenas en el sur de Baja California, los intentos de explicación de estas sociedades no están exentos de un evolucionismo unilineal que las considera en la escala más baja del progreso humano y es tan sólo en los últimos años cuando se ha hecho una revaloración de "la verdadera complejidad y la diversidad que entrañan" estos pueblos (Rodríguez Tomp, 2006: 15).

Es precisamente en este énfasis evolucionista dado por Kirchhoff a los escritos de Baegert en el que acentúa su principal valor etnográfico. Uno de los motivos de Kirchhoff para impulsar la publicación y la difusión del texto en español es el haberlo considerarlo una fuente indispensable "para el estudioso de formas primitivas de la vida humana". Kirchhoff adjudica a Baegert un tono "pesimista" y "realista" lo cual explica fue "engendrado" por el hecho de atestiguar durante años el "espectáculo de una vida tan primitiva" (Kirchhoff, en Baegert, 1942: XX). La imagen que Kirchhoff pergeña de Baegert es la de un eremita, y no pasa desapercibido que aún subsistan en su criterio de apreciación ecos de las ideas gestadas a partir del siglo XVI en torno a la influencia que el medio
2. Véase Ignacio del Río 1984. También conviene tomar en cuenta la observación de Mary Louise Pratt sobre el viraje epistémico gestado a partir del decenio de 1980, lo cual no excluye tendencias y esfuerzos anteriores a esta fecha, en el análisis, interpretación y uso de las fuentes de origen colonial y de sus relaciones sobre los Otros: "En las últimas décadas del siglo XX los procesos de descolonización iniciaron el cuestionamiento de la facultad del imperio para construir significado. Ese conocimiento se enmarca en un trabajo de gran escala dirigido a descolonizar el conocimiento, la historia y las relaciones humanas" (Pratt, 2010: 21). 
geográfico y cultural del Nuevo Mundo ejercía sobre los europeos, al grado de transmitirles sus taras:

No nos puede sorprender que los habitantes de ese rincón de la península reflejasen en su cultura la pobreza y el aislamiento de su tierra; ni nos puede sorprender que un hombre, que durante tantos años vivió solo entre ellos, divorciado no sólo de la cultura europea en la cual se había formado, sino aislado hasta de lo poco de esta cultura que los jesuitas habían logrado transplantar a otros lugares de la Baja California, supiese captar mejor que otros lo primitivo $\mathrm{y}$ atrasado de la vida de sus feligreses, dándonos un libro cuyo realismo y pesimismo buscan su igual en toda la literatura misionera (Kirchhof en Baegert, 1942: XX-XXI).

En los hechos, y de esto es posible que Kirchhoff no tuviera conocimiento, Baegert mantuvo comunicación epistolar con su familia como lo demuestra la publicación de una parte de la correspondencia con sus hermanos y madre que suman en total más de 271 páginas escritas entre 1749 y 1761 (Baegert, 1982). El que estos grupos humanos no emplearan tecnologías complejas y se concentraran en "actividades de apropiación" como la caza, la pesca y la recolección:

podría hacernos pensar que su existencia se desarrolla a partir de un eterno deambular buscando el sustento, sin que puedan disponer de una parte de su tiempo para la satisfacción de otras exigencias de la vida humana, tales como las de carácter social o espiritual (Rodríguez Tomp, 2006: 16-17).

En este punto hay que remarcar también como un elemento distintivo de esta ausencia de tecnología compleja, la falta de un sistema de escritura. Rodríguez Tomp indica que esta idea fue puesta en duda por Marshall Sahlins, entre otros, al proponer el concepto de "sociedad originaria de la abundancia" (original affluent society) basado en el análisis de varias sociedades de este tipo en el mundo en las que se encontró que sólo bastan unas horas de recorridos para satisfacer las necesidades básicas de una comunidad, con lo que queda lugar para una diversidad de actividades extra alimentarias (Rodríguez Tomp, 2006: 17). De este modo, también estos grupos de "cazadores recolectores" son poseedores de una vida religiosa estrechamente ligada por razones de subsistencia a "la naturaleza", de ahí que se enfoquen en las plantas, los animales, el paisaje y sus cambios, y los fenómenos meteorológicos y astronómicos (Rodríguez Tomp, 2006: 17).

\section{Estructura de la obra}

La obra de Juan Jacobo Baegert fue publicada por vez primera en 1771 en lengua germana en Manhein. Un año después se hizo una segunda edición en la misma ciudad con algunas correcciones y adiciones a cargo del autor (Baegert, 1952: V). La edición completa en español hecha en 1942 por Paul Kirchhoff, titulada Noticias de la península americana de California, se basó en esta segunda edición que es la que hemos consultado para el presente artículo, apoyándonos además en la versión digitalizada de una reimpresión en alemán fechada en 1773 y de algunas reimpresiones en español e inglés citadas en este texto. La obra está dividida en tres partes: una primera correspondiente a asuntos geográficos y recursos naturales como flora, fauna y minerales, bajo el título "De California en general, su carácter, clima y productos". En esta parte, el autor recoge los criterios renacentistas, que encuentra su raíz más 
clara en Michel de Montaigne, ${ }^{3}$ al preocuparse por dar a conocer al lector las características del espacio físico donde acontece la narración; de esta manera prepara el escenario para después introducir a los personajes que ocuparán dicho espacio desde una óptica que busca constituirse en un discurso objetivo que detalla y cataloga la relación de objetos ahí dispuestos. La segunda parte se denomina "De los habitantes de California", allí discurre y moraliza acerca de las costumbres, aspecto y pensamiento de los indígenas. La tercera y última parte se denomina "De la llegada de los españoles a California e introducción de la fe cristiana; de las misiones y otras cosas anexas", es aquí donde la presencia de los "españoles" se despliega dentro de la narración en función del papel que desempeñaron para "redimir" a los indígenas de su ignorancia en la fe cristiana.

La estrategia seguida en la estructura de la obra buscó resaltar el contraste entre el antes y el después de la instauración del cristianismo en Baja California. El texto está ordenado conforme a un estilo constante en las relaciones de viajeros europeos que desde el descubrimiento del Nuevo Mundo se dieron a la tarea de inventariar el globo bajo el impulso de criterios de cuño racionalista y teológico. Acorde a Tzvetan Todorov, la obra Nouveaux voyages, memories de l'Amerique septentrionale y Dialogues curieux entre l'auteur et un sauvage sobre los hurones, publicada en 1703 por el barón de Lahontan fue fundamental para apuntalar este modelo literario. Se trata de una trilogía cuyo segundo volumen es un tratado compuesto de capítulos dedicados a la fauna, la flora, la arquitectura, las creencias de los "salvajes", sus amores, enfermedades, guerras, además de incluir un breve léxico sobre su lengua (Todorov, 1991: 312). Todorov consideró que Lahontan se valió de un molde propuesto en la segunda mitad del siglo XVI por Montaigne en su escrito sobre "Los caníbales", de amplia circulación en las décadas y siglos posteriores, que sentó las bases para las futuras representaciones del buen salvaje a partir de la exposición de las costumbres de los pueblos indios americanos (Todorov, 1991: 60). En complemento a lo dicho por Todorov conviene señalar que la obra de Montaigne tuvo al menos dieciocho ediciones y reimpresiones -Francia, Holanda e Inglaterra- entre fines del siglo XVI y mediados del XIX, que lo han hecho ser considerado el autor más leído en Francia, sólo atrás de Voltaire. ${ }^{4}$

$\mathrm{Al}$ igual que Baegert, otros jesuitas asignados en "zonas de contacto" del Nuevo Mundo, entre los que se cuentan Miguel del Barco (1973) para el caso de California, o José Cardiel (1989), José Sánchez Labrador (1936) y Tomás Falkner (De Angelis, 1969) en el Río de La Plata, son deudores de los modelos propuestos en un primer momento por Montaigne, y después por Lahontan, entre otros, consistente en la abundancia de descripciones sobre las características geográficas, etnológicas y culturales y en detalles de los territorios y grupos humanos que encontraron y que, más tarde, serían profundizados durante la Ilustración. También es preciso mencionar las similitudes entre Montaigne, Étienne de La Boétie, Tomás Moro y Erasmo respecto a su crítica a ciertas leyes y costumbres inequitativas y de explotación de los seres humano, vigentes en las sociedades europeas, y en sus aportes a la construcción dicotómica del buen salvaje en ultramar, un estilo que subsiste en el texto de Baegert. ${ }^{5}$

Los misioneros jesuitas de mediados del siglo XVIII se destacaron por su tendencia testimonial. Una vez lanzados al exilio, tras su expulsión del Imperio español mediante el decreto de Carlos III con fecha del 27 de febrero de 1767, los jesuitas se valieron de sus anotaciones recabadas durante años de servicio en las misiones para dar cuenta de sus experiencias y conocimientos en torno a esas latitudes. En palabras del historiador decimonónico argentino Pedro de
3. A propósito del estilo renacentista de Montaigne y de su influencia en escritores posteriores véase el prólogo de Emiliano M. Aguilera a los Ensayos completos de Montaigne (2011 [1580-1588]) en sus Ensayos completos y el análisis que le dedica Tzvetan Todorov (1991).

4. Véase Aguilera (en Montaigne, 2011 [1580-1588]: XIX).

5. A fines del siglo XX el antropólogo Nigel Barley apuntó: “Actualmente el hombre primitivo es utilizado por los occidentales, igual que lo fue por Rousseau o por Montaigne, para demostrar algo referente a su propia sociedad y reprobar los aspectos de la misma que les parecen poco atractivos" (1994: 121). 
Angelis, los jesuitas acusaron un ímpetu enciclopedista que los llevó a incursionar en campos tan diversos como la etnología, la lingüística, la historia, la botánica, la zoología y la cartografía (De Angelis, 1969).

Una notable diferencia en la tendencia asumida por los escritores del siglo XVIII que se ocuparon del continente americano y de otras regiones consideradas "exóticas", es decir, aquellas que no eran los centros de poder en Europa occidental respecto a sus antecesores del siglo XVI, fue la de dotar a la naturaleza de un mayor protagonismo -tendencia menos denigrante sobre esos territorios y sus habitantes. En palabras de Antonello Gerbi: "El continente que en el siglo XVI había suscitado tantos problemas filosóficos y teológicos, cosmográficos y políticos ahora, tras el eclipse de la era barroca, se representaba como Naturaleza y como Clima a los espíritus prácticos y apasionados del XVIII" (Gerbi, 1982: 55). Esto no supuso que dejaran de publicarse ideas denigrantes y peyorativas sobre América y sus habitantes. De hecho, Gerbi señala que en el "lugar y año del más glorioso y triunfante enciclopedismo", refiriéndose a Berlín en 1768, se publicó Recherches philosophiques sur les Américains, ou Mémoires intéressants pour servir à l'histoire de l'espèce humaine de Corneille de Pauw, a la que designó como la obra cúspide de "la denigración de toda la naturaleza americana" después de los textos del naturalista Buffon (Gerbi, 1982: 66).

A mediados del siglo XVIII la forma de describir, concebir y relacionarse desde Europa con el resto del mundo cambió sustancialmente, sobre todo con la conformación de la disciplina designada como historia natural que propuso un tipo de conocimiento inédito al introducir una "tarea universal y secular que, entre otras cosas, hizo de las zonas de contacto un sitio de trabajo manual e intelectual, e instaló allí la distinción entre ambos" (Pratt, 2010: 59 y 64). Esta tarea se sustentó en esquemas de clasificación totalizadores como los de Linneo y Buffon (Pratt, 2010: 65). A partir de entonces se sistematizó la naturaleza y todas las expediciones y viajeros, con formación científica o sin ella, procuraron recolectar ejemplares, crear colecciones, denominar nuevas especies, reconocer las ya conocidas y dar cuenta de ello en libros de viajes (Pratt, 2010: 64). Esta sistematización de la naturaleza representó además de un discurso europeo sobre mundos no europeos, un discurso urbano sobre mundos no urbanos "y un discurso burgués y culto acerca de mundos campesinos e incultos" (Pratt, 2010: 78).

\section{Baegert: el autor}

Pese a las autodeclaradas "pobres consideraciones" que le merecía la tierra donde había pasado diecisiete años, el misionero redactó un largo y detallado informe acera de la geografía, el clima, la flora, la fauna, la labor misionera y las características físicas, culturales y sociales de los indígenas. ¿Por qué Baegert dedicaría sus últimos esfuerzos para dejar en papel su opinión sobre una tierra que valía "tan poca cosa"?

Es importante tomar en cuenta algunas circunstancias de Baegert relacionadas con su origen y su estadía en la península de California. El misionero jesuita nació en Schlettstadt (Alsacia) en 1717, fue el cuarto hijo de un total de siete, cuatro varones y tres mujeres. Su padre era de oficio talabartero mientras que su madre se dedicó a la crianza de los hijos y al hogar. Juan Jacobo y sus tres hermanos se dedicaron al sacerdocio, uno en el clero secular, otro en la orden de los capuchinos y él -junto con su hermano Francisco Javier- en la Compañía 
de Jesús; además, dos de sus tres hermanas abrazaron la vida religiosa. ${ }^{6}$ De regreso en Europa tras la expulsión de la Compañía del Imperio español, Baegert residió entre 1769 y 1772 -este último, año de su muerte- en el colegio jesuita de Neustadt, en la población de Haardt en Renania Palatinado. ${ }^{7}$

Juan Jacobo Baegert fue ordenado sacerdote en 1747 y dos años después partió como misionero a Nueva España. El 7 de mayo de 1751 tocó suelo en Baja California y a fines de mayo arribó finalmente a la misión de San Luis Gonzaga, ${ }^{8}$ fundada en 1737 en un área habitada por los pueblos guaycura en tierras interiores a la altura de la latitud 25 grados norte. Según Kirchhoff, esa misión era la más aislada y pobre del sistema misional jesútico en California, y a ello se debió que Baegert tuviera escasa correspondencia con sus compañeros de la Orden.

El bucólico paisaje descrito por Kirchhoff le ayudó a explicar el dejo pesimista que encontró en la obra de Baegert (Kirchhoff en Baegert, 1942: XIX-XX). Esta falta de optimismo atribuida por Kirchhoff a Baegert no fue en menoscabo del realismo que él encontró a lo largo de la obra, la cual fue escrita con tono irónico e incisivo y una intención moralizadora dirigida a propios y extraños. Lo anterior constituye una característica narrativa subsistente en el siglo XVIII labrada desde dos siglos antes, como se aprecia en el texto de Montaigne sobre los caníbales (Montaigne, 2011: 153-163). Es perceptible en Baegert un apego a lo "natural" como oposición a los excesos de la vida material que, a decir de Bolívar Echeverría, era algo distintivo en los jesuitas durante el siglo XVIII cuando pugnaban por un "proyecto de construcción de una modernidad, de un proyecto civilizatorio moderno y al mismo tiempo - ¿paradójicamente?- católico" (Echeverría, 2000: 58). Echeverría retoma la tesis de Edmundo O'Gorman relativa a que el proyecto histórico espontáneo que inspiraba de modo dominante la vida social en América Latina en el siglo XVII no era el de prolongar o expandir la historia europea sino re-comenzar la historia de Europa, rehacer su civilización (Echeverría, 2000: 61).

Entre los motivos declarados para escribir y publicar su obra, Baegert adujo que el sólo hecho de que California ocupara una amplia extensión geográfica en el Nuevo Mundo debía atraer el interés de Europa. California se entiende así como un espacio cuyo contenido es necesario clasificar y encasillar dentro de los vastos anaqueles del conocimiento en proceso de construcción desde el siglo XVI europeo, pero que arreció desde mediados del siglo XVIII. Pratt ha indicado que en ese segundo momento emergió una nueva versión de "conciencia planetaria" europea que presentaba dos características: "una orientación hacia la exploración interior y la construcción de significado en escala global a través de los aparatos descriptivos de la historia natural." Esto dio pie a la construcción de un eurocentrismo moderno (Pratt, 1997: 44). De acuerdo con esta autora, se trató del nacimiento de las ciencias naturales lo que supuso un cambio en la manera en que las élites europeas se comprendían a sí mismas y a sus relaciones con el resto del mundo (Pratt, 2010: 44).

Fue a partir de clasificaciones como la emprendida por Baegert que California se incorporó al mundo cristiano, así se tratara de los confines del Imperio español. La frase inicial con que inicia el libro de Baegert no deja lugar a dudas sobre su cometido:

Todo lo concerniente a California es tan poca cosa, que no vale la pena alzar la pluma para escribir algo sobre ella. De miserables matorrales, inútiles zarzales y estériles peñascos; de casas de piedra y lodo, sin agua ni madera; de un puñado
6. Véase Introducción y Notas de Schulz-Bischoff y Nunis, (en Baegert, 1982: 19-21).

7. Véase Notas de Schulz-Bischoff, (en Baegert, 1982: 17).

8. Véase Introducción de Nunis, (en Baegert, 1982: 20-21). 
9. En la edición en alemán de 1772 dice: "so mohl in Mexico als zu Madrit".
10. Baegert aclara que recorrió California en su parte "conocida", que correspondía a un poco más de la mitad de la superficie peninsular; es decir, aquella que en la práctica había sido incorporada al sistema misional y que cubría del extremo sur hasta un poco al norte del paralelo $28^{\circ}$. de gentes que en nada se distinguen de las bestias, si no fuera por su estatura y capacidad de raciocinio, - ¿qué gran cosa debo qué puedo decir? Sin embargo, en vista de que California forma una no pequeña parte del Nuevo Mundo, del que se quieren noticias en el viejo continente; debido a también a que todos los geógrafos y cosmólogos la mencionan, sin que ninguno de ellos diga la verdad; debido asimismo a que últimamente se ha puesto el grito en el cielo, tanto en México como en España, ${ }^{9}$ por sus riquezas imaginarias, del cual alboroto algo ha volado, tal vez también hasta Alemania; $y$, finalmente, debido a que en Europa se oye platicar y se lee con no menos interés algo sobre la pobreza y miseria de tierras lejanas o sobre la estolidez y vida bestial de pueblos de ultramar, que sobre sus artes y buen gobierno; debido a todo esto, en fin, he tomado la resolución de acceder a los ruegos de muchos y otras personas de respeto, y responder, al mismo tiempo, por medio de una descripción de este país y otras cosas anexas (Baegert, 1942: 3).

Para Baegert bastaba darse a la tarea de escribir sobre California por el sólo hecho de que ésta formaba parte del Nuevo Mundo, esa particularidad era suficiente para que la cristiandad la conociera con precisión y objetividad, incorporándola con ello al imaginario cristiano. La segunda consideración de Baegert era para refutar la proliferación de noticias inexactas sobre esas tierras distantes, propaladas por geólogos y cosmólogos que la situaban y describían erróneamente en sus mapas y tratados geográficos. El valor testimonial es aquí enfatizado en especial por proceder de un "hombre de Dios", despojado de todo fin lucrativo cuya única aspiración era la salvación de esas primitivas almas "gentiles". El tercer motivo que perseguía era responder a las ideas equivocadas que circulaban en torno a las supuestas riquezas que albergaba esa tierra yerma. Más específicamente, este último planteamiento se daba en descrédito de los jesuitas, pues validaba la versión de que su presencia por siete décadas en California les había redituado enormes riquezas. Un cuarto y último factor, que se entrevera con el primero de estos propósitos, era responder al creciente interés en Europa por conocer las formas de vida de otras latitudes en atención a los afanes enciclopédicos de sus contemporáneos, aun cuando Baegert adhería a ciertos fundamentos del neoclasicismo alemán que, a decir de Adam Kuper (2001: 24), buscaban hacer frente a las pretensiones materialistas y racionalistas de origen francés, centradas en registrar, catalogar y sistematizar -de manera obsesiva- los datos de grupos humanos y elementos naturales en el mundo. Sin embargo, el poder que iba ganando la ciencia durante la segunda mitad del siglo XVIII era tan avasallador que incluso se sobrepuso a "las más intensas rivalidades nacionales" en Europa (Pratt, 2010: 48). Este hecho no significó que la competencia entre las potencias europeas continuara "siendo el motor de la expansión europea en ultramar", aunque fuera impulsada por la búsqueda de riquezas y por acrecentar el conocimiento del mundo (Pratt, 2010: 49).

Baegert sustentó su autoridad en la materia en virtud de su larga experiencia misional, durante la cual afirma que recorrió la península de norte a $\operatorname{sur}^{10}$ y de costa a costa. Él se presentaba como portador de las experiencias comunicadas por otros misioneros que habían permanecido en ese territorio por más de 30 años. Al igual que otros jesuitas como Francisco Javier Clavijero y Miguel del Barco, Baegert reconoce que su primer impulso por escribir sobre California obedeció a la lectura de una parte de las Noticias de la California de Miguel Venegas, publicada en Madrid en 1757. La principal objeción de Baegert a ese texto proviene del hecho de que Venegas nunca estuvo en California, de ahí su empeño en intentar responder a las inexactitudes de ese autor aunque 
admite que sólo tuvo acceso a la traducción francesa, de extensión más corta que la castellana.

El estilo narrativo de Baegert es pretendidamente menos barroco que el de los autores españoles a quienes fustiga por su tendencia a llenar varias páginas con referencias escolásticas que nada más lograban encarecer el costo de los libros, sin que hubiese relación con los temas abordados. Baegert aclara que se propuso evitar ese tipo de desvaríos para ocuparse únicamente de lo relacionado con California; sin embargo, incluyó un capítulo denominado "algunas moralejas y del Capítulo IX de la Parte Tercera, que no corresponda a California de una manera directa". El autor jesuita justificó su proceder aduciendo que con eso buscaba "satisfacer en parte, y estimular por la otra, el loable interés y la curiosidad del lector" (Baegert, 1942: 5). De igual manera, se excusa por su modo de escribir "áspero y chocante" y por sus errores ortográficos de lo cual culpa al hecho de haberse expresado poco en su idioma materno, incluso "casi" olvidarlo, durante los diecisiete años que vivió de misionero. Sus críticas al estilo barroco español y a los excesos retóricos quedan manifiestos cuando Baegert aclara al lector que su renuencia a abrazar "ciertos modernismos", que encontró a su regreso al "Rhin", se debe a que le parecen "amanerados" o "innecesariamente reintroducidos de tiempos remotos" (Baegert, 1942: 8). El consciente estilo narrativo asumido por Baegert debe enmarcarse como parte de los cambios introducidos por el creciente predominio de la historia natural durante la segunda mitad del siglo XVIII. Así, por ejemplo, los "escritores viajeros" se apartaron de "tradiciones tales como la literatura de supervivencia, la descripción cívica o la narrativa de navegación, para dedicarse íntegramente al nuevo proyecto de construcción de conocimiento que proponía la historia natural" (Pratt, 2010: 59).

De igual manera es sobresaliente el intento de Baegert por distanciarse culturalmente de lo español no sólo en el estilo narrativo sino al introducir un elemento relativista, cuando al referir a los nombres de cosas o frutos antepone la expresión: "que los españoles llaman". Se ha indicado que una costumbre particular de los jesuitas en el siglo XVIII era que una buena proporción de sus textos fueran escritos en latín, entre las que intercalaban algunas frases o palabras en francés y español. ${ }^{11}$ Pero en el caso de Baegert, el libro sobre California fue escrito en alemán valiéndose de vocablos en español cuando lo consideró necesario, como al señalar nombres topográficos o de plantas y animales. Por el contrario, las cartas que dirigió a sus hermanos en Alemania quienes, coma ya se mencionara, también ejercían el sacerdocio, fueron redactadas en latín.

Cabe destacar asimismo que Baegert usara el término México y no el de Nueva España. Esto queda manifiesto en diversas ocasiones; por ejemplo, en el mapa de California y la contracosta que ilustró la edición alemana de 1772, basado en el del jesuita croata Fernando Consag, donde se lee sobre el territorio sonorense "Pars regni mexicani"; o en otro pasaje donde alude "oder gar mit den mexicanischen landscricht dereignit", ${ }^{12}$ por mencionar algunos casos. Para la época en que fue publicado el libro había un notable contexto de surgimiento de un nacionalismo criollo protomexicano. David Brading sostiene que para el decenio de 1750 "la vida intelectual mexicana" se caracterizaba por poseer "una confianza renovada y un patriotismo más intenso" (Brading, 2004: 29). Por su parte, el igualmente connotado historiador Roberto Moreno describió de esta manera el clima ideológico experimentado por los estudiosos criollos mexicanos contemporáneos a Baegert:
11. Véase Introducción de Nunis (en Baegert, 1982: 10).

12. "o incluso con el desmantelamiento de tierras mexicanas". 
La historiografía dieciochesca sobre nuestro pasado prehispánico no está, ni con mucho, cabalmente estudiada. Ya se la considere como una característica del movimiento ilustrado en estas tierras o inmersa en una corriente más amplia de formación de la conciencia nacional, no cabe duda que su análisis completo requiere aún de dar a luz muchos testimonios, revalorar algunos que ya poseemos y buscar cuidadosamente otros de los que consta su existencia. Los autores novohispanos que en la segunda mitad del siglo XVIII escribieron sobre antigüedades mexicanas forman un número sorprendentemente grande. Empero, pocos de ellos vieron impresos sus trabajos: Granados, Alzate, León y Gama y Clavijero. Sorprende también que muchos o escribieron o intentaron escribir una historia antigua de México, así en general: Veytia, Clavijero, Díaz de la Vega, León y Gama, Granados, Sandoval y otros. No deja de ser significativo que el único que fue editado en su tiempo (lo que quizá sea una muy fuerte razón de su celebridad), fue el jesuita expulso Clavijero que radicaba en Italia y que publicó en italiano. Los otros autores han permanecido parcial o totalmente inéditos en muchos de sus escritos sobre la historia prehispánica y cada vez más requieren de atención para poder completar el cuadro de nuestros historiadores ilustrados (Moreno, 1972: 359).

En efecto el jesuita Francisco Javier Clavijero, exilado en Bolonia después de la expulsión, ha sido visto en la historiografía mexicanista como uno de los autores protonacionalistas a fines del siglo XVIII. Esta postura la dejó clara desde las primeras páginas a su celebrada obra póstuma Historia antigua de México y de su conquista:

Una Historia de México escrita por un mexicano, que no busca protector que lo defienda, sino guía que lo dirija, y maestro que lo ilumine, debe consagrarse al cuerpo literario más respetable del Nuevo Mundo, como al que, más instruido que ningún otro en la Historia mexicana, parece el más capaz de juzgar el mérito de la obra, y descubrir los defectos que en ella se encuentren.

[...]

Sabeis cuan arduo es el argumento de mi obra y cuan difícil desempeñarlo con acierto, especialmente para un hombre agobiado de tribulaciones, que se ha puesto a escribir a más de siete mil millas de su patria, privado de muchos documentos necesarios, y aun de los datos que podían suministrarle las cartas de sus compatriotas (Clavijero, 1844: III).

Baegert, por su parte, tuvo el impulso para escribir su obra sobre California destinada a sus contemporáneos y coterráneos. Sus observaciones otorgan alto valor a lo empírico, apuestan a la atestiguación directa en oposición a libros de amplia circulación sobre California como el de Venegas, escrito en base a informes de terceras personas. Así se desprende de las siguientes líneas:

[...] me he servido única y exclusivamente de mi propia experiencia, motivo por el cual solamente cito como comprobación, lo que me ha pasado a mí en persona; lo que vi y como lo vi yo mismo, o que he oído de las personas que conmigo vivieron en California (Baegert, 1942: 5).

Se trasluce la concepción de Baegert respecto al tipo de acontecimientos épicos que debe llevar una narración, por lo que previene al lector a no esperar "grandes portentos de la naturaleza, ni acontecimientos o sucesos de importancia. California no es el lugar donde ocurran, ni ha sido voluntad del Creador la de hacerlas acontecer en ella" (Baegert, 1942: 6). Como prevención ante posibles desacuerdos suscitados por su obra entre personas también conocedoras de California, Baegert se mueve con cautela y da lugar al carácter relativo que 
debe guardar toda generalización ante lo extenso, complejo y diverso que supone hablar de un tema como el de California. Previene por ello sobre lo extenso de ese país y su variedad climática y de costumbres, sobre la diversidad de tribus que la habitan, entre las que llegan a mediar distancias de "treinta y más horas" a pie. No se propone pues universalizar sus observaciones a la totalidad de California sino limitarse a lo por él conocido. No obstante la modestia aducida por Baegert sobre las razones de su escrito, y su preocupación para acotar el radio de sus potenciales lectores a aquellos en lengua germana, es de destacar que utilice la hora como unidad para medir las distancias entre un punto y otro, puesto que el valor de la legua cambia de un lugar a otro, incluso dentro de la misma Alemania, en cambio la hora "todo el mundo puede imaginárselo". Sobresale entonces el interés por emplear criterios y categorías homogéneas, asequibles a un público diverso, como era usual en la época y destaca su preocupación por buscar referencias comunes para sus lectores europeos.

Otra vez vemos reflejada la sombra de Montaigne. Es a partir de las coordenadas discursivas de Montaigne donde se sientan las bases para posteriores trabajos como el de Baegert, donde se trazan los contornos del buen salvaje en oposición al hombre civilizado presa de la razón utilitaria, el egoísmo y otros predicamentos ilustrados. A partir del elogio de las virtudes "naturales" del buen salvaje se teje una crítica mordaz, que desenlaza en una condena moral, a la sociedad europea mediante un método sencillo: las cualidades apreciadas en los salvajes son aquellas de las que carecen los civilizados (Todorov, 1991: 60). Una muestra de lo anterior es la descripción de Montaigne, en su texto sobre "Los caníbales", acerca de lo que escuchó a un grupo de estos "salvajes" en Rúan -en el noroeste de Francia- durante su cautiverio en Europa, en donde se declararon admirados de la pompa y excesos materiales de que hacían gala cierta clase de personas, mientras la otra mitad de la gente mendigaba "demacrados por el hambre y la pobreza", pero lo que más los asombró fue que los menesterosos no se rebelaran contra tal injusticia (Montaigne, 2011: 163).

En cuanto al tema central que nos ocupa, desde su exilio en Alemania se advierte en Baegert una nostalgia por California, un lamento por el destierro, sentimiento común entre los jesuitas de distintas latitudes afectados por el decreto de expulsión. Entre la ironía y el despecho enfatiza que fue contra su voluntad que los jesuitas abandonaron California, pero que "de mil ganas, en cambio, hubieran querido emprender con nosotros la retirada de esta triste tierra, los dragones españoles y sus oficiales que apenas habían llegado para expulsarnos de ella" (Baegert, 1942: 14). El trasfondo de esta expresión denota la idea presente en los jesuitas de estar cumpliendo la voluntad divina, ya que sólo los misioneros imbuidos de su compromiso por extender la palabra de Dios podían soportar condiciones extremas en tierras lejanas, sobreponiéndose a sus tribulaciones por habitar una tierra pobre y sin valor alguno.

Hay añoranza por esa vida de desprendimiento material al explicar que su traje sólo se componía de un hábito de camelote ${ }^{13} \sin$ forro y sin ropa debajo. Al igual que Montaigne, cada mención de la miseria de los indios es contrapuesta a lo dispendioso de la vida en los centros urbanos europeos y, sobre todo, de los sectores ricos de la población. Este recurso dicotómico de Baegert para contrastar realidades entre la bárbara California y la civilizada Europa es recurrente en la obra, es constante la crítica a los excesos materialistas de los europeos.
13. Tejido fuerte e impermeable, generalmente de lana. 
14. A propósito de esto, conviene tomar en cuenta la observación de Robert Darnton acerca de que los jesuitas "fueron en pos de la modernidad al mismo tiempo que perseguían a los philosophes" (2011: 243).
Pareciera que la vida en la misión templó en su personalidad un carácter ascético. Las comparaciones entre California y el entorno alemán son continuas en cuestiones de clima, fauna o de distancias entre dos localidades. De este modo reafirmaba la voluntad de proporcionar a sus lectores más próximos un referente cultural que los familiarice con el entendimiento de California.

En la estructura narrativa del libro el espacio dedicado a la presencia europea en la península californiana es ligeramente superior al espacio que se ocupa del registro de las costumbres indígenas. La disposición espacial dispuesta para tratar cada uno de estos temas es indicativa de que la llegada del cristianismo constituye para el autor una fase superior en la experiencia de los californios, es una afirmación de que la cristiandad representa un estado civilizador superior a cualquier otro -tal como lo testificó al convivir con los cazadores recolectores en California-.

Frente a la forma discursiva adoptada por Baegert queda la impresión de que en realidad lo que escribió fue una gran metáfora moral, al tomar como parangón la vida de los californios para denostar los excesos de la vida mundana cometidos por los europeos. Más que pesimismo hacia el estado social de la California sus palabras, disfrazadas de desprecio, bien pudieron estar destinadas a desalentar todo interés que esas tierras pudieran despertar entre los europeos; de este modo sus pobladores estarían libres de los excesos cometidos en las sociedades civilizadas que a su regreso encontró bastante melifluas -“amaneradas" en su propia expresión-, materialistas y liberadas o alejadas del temor a Dios. Una situación similar encontraron los jesuitas mexicanos expulsados a Europa que, al decir de Brading, hallaron desesperante "el clima de la Ilustración europea" al tener que enfrentarse con "las corrientes libertinas y escépticas que se manifestaban". ${ }^{14}$ El mismo Clavijero durante su exilio en Italia repudió las burlas a la religión y la adopción del "lenguaje de la impiedad" (Brading, 2004: 32-33).

Baegert menciona que entre los californios no se conocía la propiedad privada, ni "lo mío" ni "lo tuyo", condiciones que, apoyado en San Gregorio, solo llenan de amargura y males la vida. Sobre esta aparente miseria de los californios profundizó en las riquezas espirituales que poseían, al señalar que en apariencia no tenían nada pero poseían todo lo que querían al no querer nada y no exigir más de lo que su tierra les daba. A esto atribuyó el que casi no echaran canas y estuvieran siempre de buen humor:

\footnotetext{
Solo resta desear que los californios, que realmente gozan sobre la tierra la verdadera bienaventuranza, (después de que la fe los ha inspirado) quisiesen preocuparse un poco más por la bienaventuranza del mundo del más allá y de la vida futura.

Los que viven en Europa, pueden, ciertamente, sentir envidia por la bienaventuranza de los californios, pero solamente podrán disfrutar de ella por medio de una perfecta indiferencia ante la cuestión de poseer mucho o poco, algo o nada en este mundo, y de una completa conformidad con la Divina Voluntad en todas las contingencias de la vida (Baegert, 1942: 66).
}

Al igual que Montaigne con sus "caníbales", Baegert ponderó como virtudes de los californios su carencia de ambiciones materiales, su desconocimiento de la propiedad privada y su conformidad con los designios divinos al aceptar de buena gana lo que la naturaleza les proveía por muy raquítico que fuera. Baegert cerró este círculo virtuoso con la llegada del evangelio de la mano de su orden. Reprodujo así la concepción etnocentrista que jerarquiza determinados 
atributos europeos sobre los del resto del mundo. Pese a las difíciles condiciones materiales atribuibles a la voluntad divina, los californios no estaban en peor situación que los europeos. Vemos aquí una de sus recurrentes críticas al materialismo y excesos que advirtió entre los europeos:

Los californios no se pudren más pronto, después de muertos, de cómo se pudrirían, si en toda su vida hubieren estado envueltos en seda y terciopelo; si hubieran brillado, durante los días de su vida en oro y plata; si hubieren lucido, durante unos breves años, las mismas perlas que se pescan en su mar, como un ídolo o como una diosa, o si se las hubieran echado de grandes señores.

Tú hombre, puedes pavonearte y vestirte como quieras, pero ¡sabe! Que la tumba te espera, que la podredumbre será tu lecho y que bien pronto, los gusanos serán tus prendas. Isaías, c. 14. v. II (Baegert, 1942: 84).

Es posible ir un poco más atrás de Montaigne en la genealogía de este modelo discursivo que valora el apego a la naturaleza del salvaje sobre lo artificioso que resulta la vida de los europeos. La obra de Vespucio influyó sobre la inmediata generación de autores del siglo XVI como Tomás Moro, Montaigne, André Thevet y Jean de Léry (Todorov, 1991: 310) que, como ya se ha mencionado, sirvieron de modelos para algunos autores en los siglos venideros. Esta huella es apreciable en Baegert al contrastar el desapego material de los californios y agudizar sus comentarios sobre lo superfluo de los bienes materiales a los que son tan afectos los europeos, e incluso deslizar un velado pronunciamiento por la distribución equitativa de la riqueza:

Así es que la extremada pobreza de los californios y la absoluta falta de todas las cosas que a nosotros nos parecen indispensables para la vida humana, nos dan una demostración, de ninguna manera despreciable, que nos enseña cómo la naturaleza se conforma con tan poco y cómo con tan poco puede uno mantenerse; y que, por tanto, no es la miseria, sino una opulencia inmoderada y un exceso de lujuria, las que han inventado miles de cosas, con cuyo valor, tantos indigentes podrían y deberían ser alimentados y arropados (Baegert, 1942: 86).

En aras de reforzar la imagen primitiva de los nativos siempre se expresa de ellos el sentido colectivo, a diferencia de la forma individual en que alude a los extranjeros, misioneros, vaqueros, mineros, soldados y buscadores de perlas. Pareciera que al describir costumbres de crianza y educación entre los californios buscara denostar las ideas revolucionarias que circulaban en Europa. Lo vemos señalar que a los californios no les importaba la muerte de sus hijos y que las madres hasta se sentían aliviadas si morían sus vástagos; equipara ese desenfado con las ideas del "infame soñador J. J. Rousseau" recogidas en el Emilio, como reflejo de la moral de algunos "filósofos modernos de la cofradía de los canallas" (Baegert, 1942: 102). En este pasaje asume una posición conservadora y crítica hacia los cambios sociales y las nuevas corrientes del pensamiento vigentes en Europa, también para denostar las tendencias racionalistas de los proyectos utópicos derivados de Rousseau sobre la educación e igualdad entre los hombres; ideas que el jesuita teme que conducirán al caos y reducirán al hombre a un estado elemental como el de los californios:

Y en realidad, ¿qué autoridad puede existir, qué régimen puede haber, dónde todos son iguales; dónde nadie tiene más, ni puede tener más que su prójimo; dónde cada uno y todos juntos no poseen otra cosa que su cuerpo, su alma y su piel morena; dónde el niño, desde que sabe andar, ni siquiera obedece a sus padres, ni se siente impelido a obedecerles?

[...] 
En una palabra, ellos vivían [...] como si hubieran sido librepensadores o materialistas (Baegert, 1942: 125).

Esto remite a la oración irónica con la que Montaigne cierra su texto sobre los "caníbales", luego de ponderar su sencillez y alejamiento de fines lucrativos o de la búsqueda de recompensas materiales: "Buena cosa parece todo esto, pero, ¿vamos a tener en consideración a unos individuos que no llevan calzones?" (Montaigne, 2011: 163). Es pertinente considerar la confluencia en Baegert, junto con sus contemporáneos jesuitas, de elementos de tradición y modernidad plasmadas en sus premisas morales que mezclan resabios renacentistas e ideas humanistas reacias a un mercantilismo creciente y con una oposición a los postulados universalistas y racionalistas de la Ilustración.

Un estudioso de la teología jesuítica en Nueva España ha sugerido que la Compañía de Jesús intentó construir en este virreinato "un modelo alternativo de modernidad, a la modernidad espontánea y ciega de la acumulación del capital, progreso y razón autónoma" (Kuri, 2000: 8). En este punto hay plena coincidencia con el filósofo Bolívar Echeverría, quien vio en los jesuitas una fuerza crítica que propuso una modernidad "alternativa". En palabras de Echeverría:

Los jesuitas fueron el elemento motor del Concilio de Trento y de la iglesia posterior, al impulsar un proyecto político-religioso cuidadosamente estructurado, de inspiración moderna, un proyecto ambicioso que pretendía actualizar la vida de la comunidad universal, armonizarla con los tiempos al reconstruir y reconstituir el orden cristiano del mundo, entendiéndolo como orden católico, apostólico y romano (Echeverría, 2000: 70).

Si nos atenemos al contexto vivido por Baegert a su regreso a Europa, uno se percata de que el misionero estaba imbuido de las objeciones que a mediados del siglo XVIII comenzaron a hacerse en Alemania, y en otras partes de América y Europa, contra el enciclopedismo racionalista francés; una confrontación que de manera esquemática Adam Kuper circunscribió a un debate entre la perspectiva alemana del Kultur y la visión francesa encarnada en la noción de civilization (2001: 24). Baegert tenía motivos suficientes para subirse a la palestra y combatir las ideas generadas en los círculos franceses y expandidas a los círculos intelectuales en Europa y América acerca de la primacía de la ciencia y la razón, puesto que la Iglesia era señalada como fuente de irracionalidad y superstición, y las artes y los valores espirituales eran desplazados por las expresiones del materialismo y el genio individual. Este tipo de argumentaciones sirvieron para denostar las actividades de los jesuitas en los dominios españoles que condujeron a su expulsión (Kuri, 2000: 8). De nuevo, la coincidencia con Echeverría es evidente pues éste rechazó la idea de "contrarreforma" adjudicada a los jesuitas en el Concilio de Trento, toda vez que la Compañía no buscaba combatir la Reforma sino rebasarla por considerarla insuficiente y regresiva. No buscaban frenar el Progreso y opacar las Luces, querían replantear y trascender la problemática que dio lugar a los movimientos protestantes (Echeverría, 2000: 68). Así, lo que se planteó en Trento fue "restablecer la mediación eclesial entre lo humano y lo otro, lo divino; una mediación cuya decadencia -así lo interpretan los jesuitas- ha sido el fundamento de la Reforma, de una respuesta salvaje, brutal, a esa ausencia de mediación" (Echeverría, 2000: 68). 


\section{Corolario: algunos usos etnohistóricos de la obra de Baegert}

Kirchhoff tituló su introducción a Baegert de la siguiente manera: "Las tribus de la Baja California y el libro del P. Baegert"; con ello, el arqueólogo alemán sentó, sin proponérselo, las bases para posteriores interpretaciones que concibieron a los indígenas de la península como sociedades inmutables en el tiempo, anquilosadas cultural y socialmente, sin muestra alguna de cambio cultural pues, desde su punto de vista, los indígenas peninsulares al adentrarse en el territorio miles de años atrás quedaron atrapados en "un callejón sin salida" (Kirchhoff, en Baegert, 1942: XIII-XIV). Al discutir las diferencias culturales entre los diversos grupos de la península al momento del contacto con los jesuitas Kirchhoff rechazó la explicación de inmutabilidad en sus costumbres y hábitos, y sí reconoció que estaban sumidos para entonces en "un proceso general de estancamiento y empobrecimiento" (Kirchhoff en Baegert, 1942: XXXVI). Kirchhoff matizó este aspecto involutivo entre los pueblos con los que convivió Baegert, lo que brinda a la labor misional un cariz heroico y salvador:

Los guaicuras de Baegert, desde cierto momento de su historia en adelante, no sólo no siguieron subiendo, sino, por la lógica de los procesos históricos que a ningún pueblo permiten quedarse más de un breve momento en el mismo punto de su evolución, comenzaron a bajar y seguían bajando cuando nuestro autor los conoció (Kirchhoff en Baegert, 1942: XXXVII).

El celebrado historiador Miguel León-Portilla fue más lejos al escribir que al momento de contactar indígenas y misioneros: "En cierto modo puede afirmarse que los niveles de desarrollo prehistórico que perduraron hasta los comienzos del periodo misional, constituían casos extremos de 'fosilización cultural de un género paleolítico superior'" (León-Portilla, 1995). Pese a este tipo de exabruptos, hay que reconocer la riqueza informativa extraída de la obra de Baegert. Kirchhoff resalta su característica "etnográfica, esencialmente una monografía tribal basada en las observaciones personales del autor" (en Baegert, 1942: XIX). No escapó al ojo avizor de Kirchhoff el hecho de que detrás de la exposición del jesuita se ocultaban ecos de las voces de los indígenas californios sepultados bajo el enorme peso del discurso hegemónico cristiano europeo.

Kirchhoff valoró la obra por considerarla una fuente excepcional para "el estudioso de formas primitivas de la vida humana". Su apreciación está influida por un determinismo geográfico al decir que la influencia en el ánimo de Baegert fue "resultado del ambiente" natural al que estuvo sometido. Aunque Kirchhoff reconoció una impronta realista en el texto no estuvo exento de apreciaciones anacrónicas al señalar que a Baegert, "para la observación de ciertos fenómenos le faltaban ojos" (Kirchhoff, en Baegert 1942: XXI).

Hay una preocupación conceptual notoria en Kirchhoff al momento de cuestionar el sentido otorgado por Baegert a la palabra tribu. Una vez analizados los pasajes en los que el misionero empleó ese término, se inclina a pensar que le otorgaba la connotación de ranchería; esto es, de unidades de organización social y política de los indígenas dentro de su condición de nómadas. Kirchhoff hizo una lectura que fue más allá de la anécdota y de las circunstancias descritas al aventurar hipótesis sobre las costumbres descritas, además de indagar entre líneas y extender las aportaciones del documento al grado de que pareciera que estamos frente a una fuente originada por uno de sus colegas etnólogos, no obstante advertir una incomprensión teórica de Baegert respecto a las situaciones observadas. ${ }^{15}$
15. En este punto conviene indicar lo anacrónico de este reclamo, acorde a Leclercq el concepto de sociedad "como realidad sui generis" era inexistente en el siglo XVIII (1973: 243). 
16. Cabe aclarar que el el trabajo de Rodríguez Tomp es parte de un amplio proyecto editorial de la oficina mexicana encargada de asuntos indígenas.
Desde una postura influida por el estructural funcionalismo, el historiador Ignacio del Río atribuyó a los indígenas una paulatina reincorporación de parte de sus tradiciones a la cosmovisión cristiana; a su juicio estas prácticas resignificadas desarticularon las funciones originales de los mitos y rituales indígenas provocando un deterioro en su estructura social que, a la postre, condujo a su desaparición -aunado a las devastadoras epidemias y alteraciones de su frágil equilibrio con el medio ambiente-. En el avance de sus explicaciones, del Río intercaló citas textuales de Baegert con comentarios propios, de tal forma que la autoridad de su fuente "primaria" le permitiera reforzar y resaltar algunas de las costumbres descritas de los indígenas y los aspectos cotidianos acaecidos dentro de la misión. Del Río dio a Baegert una calidad casi infalible en tanto testimonio directo de los hechos narrados. Algo que distingue la obra de del Río es la aplicación del concepto de aculturación para explicar el contacto entre dos culturas, la cristiana y la de los indígenas, y pese a establecer que jerárquicamente los colonizadores fueron los dominados no deja de lado que en los hechos se trató de un intercambio de "rasgos culturales", al grado de que pareciera que el intercambio fue recíproco aunque bajo un sesgo violento y hegemónico:

En realidad todos los individuos involucrados en el contacto eran potenciales agentes del cambio cultural; pero los jesuitas y el resto del grupo inmigrante tuvieron, por su posición de dominio, una mayor capacidad que los nativos para promover tal cambio y adecuarlo a sus particulares intereses (del Río, 1984: 163).

Un esfuerzo notable por traspasar la mera reproducción de fragmentos testimoniales es el de Rosa Elba Rodríguez Tomp, quien al conjuntar herramientas metodológicas de la antropología y la historia para interpretar el encuentro cultural entre cristianos e indígenas desde una mirada subalterna. Ella retoma la hipótesis de aculturación planteada por del Río pero va más allá al ahondar en la relación hombre-naturaleza mantenida por los indígenas y el perjuicio provocado al verse modificada esa relación. De igual modo, ha sido crítica con las posturas estáticas de "fosilización" que formulara León-Portilla y el uso peyorativo de estos autores para el término "primitivo" (Rodríguez Tomp, 2002: 21). Esta autora reconoció la ironía implícita en el aparente discurso pesimista de Baegert, aunque quizá por los objetivos de su obra, el tratar de dar voz a los indígenas, ${ }^{16}$ no se detuvo a indagar sobre los propósitos de tal ironía. En suma, los esfuerzos de Rodríguez Tomp son una acertada prolongación de las perspectivas pioneras de Ignacio del Río, donde es evidente el deseo de trascender más allá de la mera cita textual y de indagar detrás del discurso dominante de los misioneros, a diferencia de intentos anteriores en los que los testimonios de los jesuitas fueron sacralizados y tomados al pie de la letra sin cuestionamiento alguno. Rodríguez Tomp sí coloca en el centro de la discusión el rol de otredad asignado al indígena e intenta levantar la lápida discursiva que pesa sobre los sujetos subalternos para hacer audibles las disonancias ocultas bajo el vociferante discurso civilizador.

En el contexto misional dirigido por los jesuitas el indio fue concebido como un ser asimilable, un receptor pasivo de la cultura representada por los religiosos, se les percibió como un lienzo en blanco, un ser en estado puro, salvaje, natural. La descripción de Baegert recoge la forma en que los indígenas fueron proyectados desde el imaginario católico europeo, lo que socava las lecturas meramente testimoniales de los misioneros. Para Leclercq, apenas quedaba duda de que los "salvajes" eran los representantes contemporáneos de los hombres de origen o próximos al origen: 
El origen es concebido por el siglo XVIII como lo auténtico, en tanto que en el siglo XIX será concebido como lo simple (lo tosco) y lo inacabado. En la medida en que el origen es lo auténtico, se pueden obtener de él enseñanzas teóricas y prácticas (morales) (Leclercq, 1973: 243).

Debemos evitar endurecer los datos registrados por Baegert, se necesita confrontarlos como documentos atravesados por preocupaciones e intereses particulares y una naciente conciencia "planetaria" como señalara Pratt; no son imágenes atemporales de las sociedades indígenas ni están exentos de la influencia de grupos culturales diversos como advirtiera Kirchhoff.

Encubierto en ese dejo pesimista atribuido a Baegert, se descubren los debates contemporáneos derivados del auge de las ideas ilustradas de cuño francés. Los numerosos cambios culturales, sociales, políticos, económicos, e ideológicos intensificaron las discusiones de larga data que oponían materialismo y espiritualidad, modernidad y tradición o ciencia y razón ante el pensamiento religioso.

\section{Agradecimientos}

Agradezco mucho las aportaciones, las sugerencias y la atenta y minuciosa lectura dada a una primera versión de este texto por parte de los dictaminadores anónimos, cuya pertinencia académica ha sido de notable ayuda para mejorar sustancialmente el mismo al ampliar el estado de la cuestión e incorporar una serie de recomendaciones de orden teórico y metodológico. Desde luego, que toda deficiencia que aquí persiste es solo responsabilidad mía. 


\section{Fuentes citadas}

» Baegert, J. (1773). Nachrichten von der Amerikanischen Halbinsel Californien mit einem zweyfachen Anhand falscher Nachrichten, Mannheim. Disponible en Internet: https:// www.biodiversitylibrary.org/item/159187\#page/7/mode/1up. Consultado el 3 de febrero de 2018 .

»Baegert, J. (1942). Noticias de la Península americana de California/por el Rev. Padre Juan Jacobo Baegert. Introducción P. Kirchhoff; traducción P. R. Hendrichs. México, Antigua Librería Robredo de José Porrúa e Hijos.

» Baegert, J. (1952). Observations in Lower California. Traducción, introducción y notas M. M. Brandenburg y C. L. Baumann. Berkeley/ Los Angeles, University of California Press.

"Baegert, J. (1982). The Letters of Jacob Baegert, Jesuit Missionary in Baja California1749-1761. Introducción y edición D. B. Nunis; traducción E. Schulz-Bischof. Los Angeles-California, Dawson's Book Shop. 


\section{Q Bibliografía citada}

Angelis, P. de (1969). Colección de obras y documentos relativos a la historia antigua y moderna de las provincias del Río de La Plata II. Buenos Aires, Andrés M. Carretero.

» Barco, M. del (1973). Historia natural y crónica de la Antigua California. Edición, estudio introductorio y notas de Miguel León Portilla. México, Universidad Nacional Autónoma de México.

» Barley, N. (1994). El antropólogo inocente. Notas desde una choza de barro. Traductor, Ma. José Rodallar. Barcelona, Anagrama.

» Bassnett, S. (2002). Translation Studies. $3^{\circ}$ edition. Londres/ Nueva York, Routledge.

» Brading, D. (2004). Los orígenes del nacionalismo mexicano. $2^{\mathrm{a}}$ edición, traducción Soledad Loaeza Grave. México, Era.

" Cardiel, J. (1989). Las misiones del Paraguay. Estudio introductorio, Héctor Sáinz Ollero. Madrid, Historia 16.

"Clavijero, F. J. (1844). Historia antigua de México y su conquista. Tomo I, traducción Joaquín de Mora México, Imprenta de Lara. Disponible en Internet: http://cdigital.dgb.uanl.mx/ la/1080023605/1080023605.html. Consultado el 23 de enero de 2018.

" Darnton, R. (2011). El beso de Lamourette. Traducido por Antonio Saborit. México, Fondo de Cultura Económica.

»Donald, M. (2004). Is a Picture Really Worth a 1,000 Words?, Review of Computers, Visualization, and History: How New Technology Will Transform Our Understanding of the Past by David J. Staley. History and Theory 43 (3): 379-385.

»Echeverría, B. (2000). La modernidad de lo barroco. 2º edición, traductor Guillermo Hirata. México, Era.

》Elias, N. (2015). Sobre el tiempo. $3^{\circ}$ edición. México, Fondo de Cultura Económica.

»Foucault, M. (1998). Las palabras y las cosas. Una arqueología de las ciencias humanas. $26^{\circ}$ edición, traducción de Elsa Cecilia Frost. México, Siglo XXI.

» Gerbi, A. (1982). La disputa del Nuevo Mundo. Historia de una polémica, 1750-1900. 2º edición, traducción de Antonio Alatorre. México, Fondo de Cultura Económica.

» Kuper, A. (2001). Cultura. La versión de los antropólogos. Traducido por Albert Roca. Barcelona, Paidós.

" Kuri Camacho, R. (2000). La compañía de Jesús. Imágenes e ideas. Scientia barroca y modernidad en la Nueva España. México, BUAP/ Plaza y Valdés Eds.

» Leclercq, G. (1973). Antropología y colonialismo. Traducido por Jesús Martínez. Madrid, Alberto Corazón.

»León-Portilla, M. (1995). La California mexicana. Ensayos acerca de su historia, México, Universidad Nacional Autónoma de México/ Universidad Autónoma de Baja California.

» Montaigne, M. de (2011 [1580-1588]). Ensayos completos. $4^{0}$ edición, notas prologales de Emiliano M. Aguilera. México, Ed. Porrúa.

" Moreno, R. (1972). Las notas de Alzate a la Historia antigua de Clavijero. Estudios de cultura náhuatl 10: 359-392. Disponible en Internet: http://www.historicas.unam.mx/publicaciones/revistas/nahuatl/pdf/ecn10/141.pdf. Consultado el 23 de enero de 2018. 
"Pratt, M. L. (1997). Ojos imperiales. Literatura de viajes y transculturación. Buenos Aires, Universidad Nacional de Quilmes.

"Pratt, M. L. (2003). Imperial eyes. Travel writing and Transculturation. $3^{\circ}$ edition. Nueva York/Londres, Routledge.

»Pratt, M. L. (2010). Ojos Imperiales, Literatura de viajes y transculturación. Traducido por Ofelia Castillo. México, Fondo de Cultura Económica.

» Río, I. del (1984). Conquista y aculturación de la California jesuítica. 1697-1768. México, Universidad Nacional Autónoma de México.

"Rodríguez Tomp, R. E. (2002). Cautivos de Dios. Los cazadores recolectores de Baja California durante la colonia. México, INI/ CIESAS.

" Rodríguez Tomp, R. E. (2006). Los límites de la identidad. Los grupos indígenas de Baja California ante el cambio cultural. México, Instituto Sudcaliforniano de Cultura.

"Sánchez Labradror, J. (1936). Los indios pampas, puelches, patagones. sin lugar de edición.

» Todorov, T. (1991). Nosotros y los otros. Traductor Martí Mur Ubasart. México, Siglo XXI. 